\title{
Income, Consumption Tendency and Per Capital Electricity Consumption in the Age of China's Urbanization
}

\author{
Ya-Yu WEN ${ }^{a}{ }^{*}$, Chong-Huai NIU ${ }^{a}$, Xi-Long YAO ${ }^{a}$ and Xiao YAN ${ }^{b}$ \\ ${ }^{a}$ College of Economics and Management, Taiyuan University of Technology, Taiyuan \\ 030024, China \\ ${ }^{b}$ College of Economics and Management, China University of Geosciences, Wuhan \\ 430074, China
}

Keywords: Urbanization; Per capital residential electricity consumption; Income effect; Electricity consumption tendency effect; Population structure effect

\begin{abstract}
The rapid development of urbanization in China is coupled with the increase in per capital electricity consumption. This study focuses on the impacts of residents' income change and consumption tendency change on per capital electricity consumption in the process of urbanization in China. In this paper, LMDI method is used to analyze each factor's impact on per capital electricity consumption in the process of urbanization in China. The results show that income effect is the major determinant of per capital electricity consumption which is followed by population structure effect and electricity consumption effect; income effect in the urban regions is more than that in the rural regions; electricity consumption tendency effect in the rural regions is more than that in the urban regions.
\end{abstract}

\section{Introduction}

Residential electricity consumption accounts for a relatively high proportion of the total electricity consumption, which keeps above eleven percent (Figure 1) ${ }^{1}$. Therefore, controlling the excessive growth of per capital residential electricity consumption is necessary to achieve Chinese energy-saving and emission-reduction targets. In order to control the total residential electricity consumption, we should pay attention to per capital residential electricity consumption and explore its determinant factors. In recent years, Chinese urbanization process has accelerated, the proportion of the urban population in the total population has increased, residents' income has continuously increased and their consumption habits have changed as well. These all have tremendous impact on the total residential electricity consumption and per capita residential electricity consumption. Therefore, it is significant to gain a deep insight into each factor's impact on per capital residential electricity consumption. 


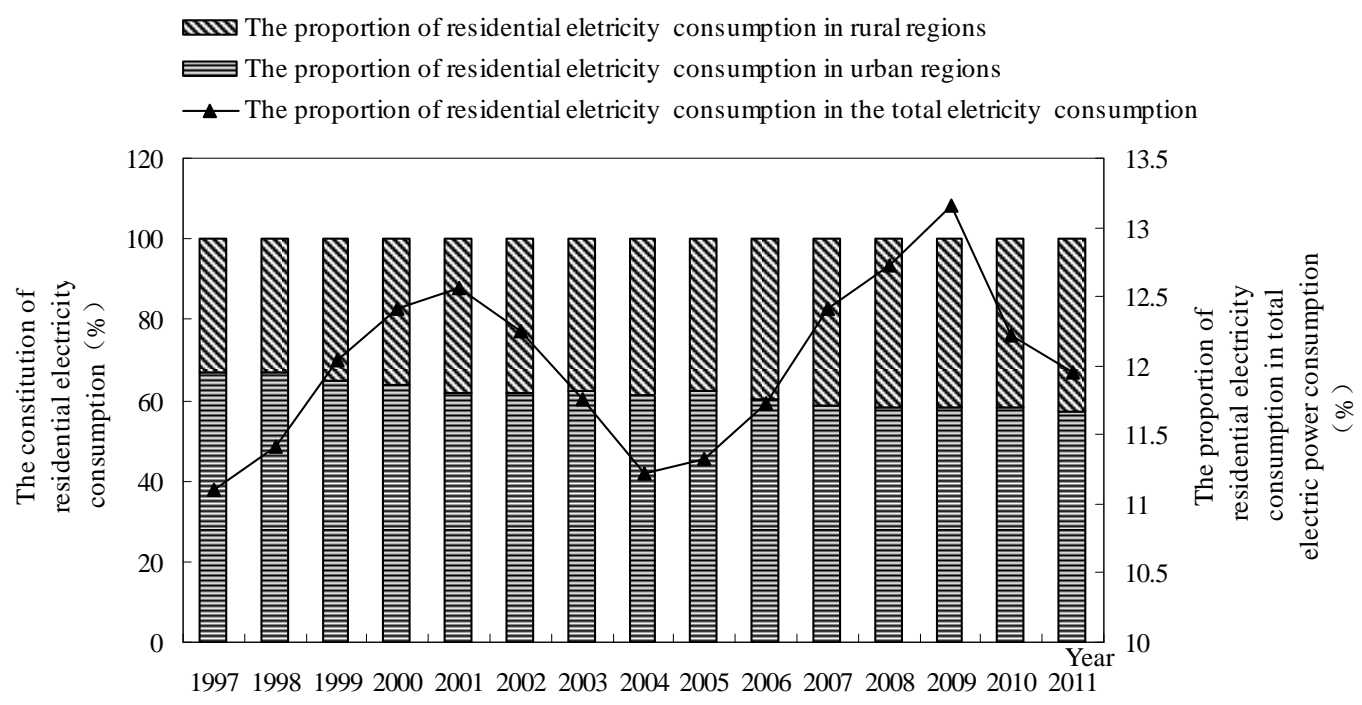

Fig.1 The situation of residential electricity power consumption in China

Many scholars have studied residential energy and electricity consumption. Most of them focused on family income's influence on residential energy and electricity consumption[1-12]. The results of these studies suggested that family income was the major influencing factor of household energy consumption. The increase in family income would increase residents' consumption capacity, particularly their consumption on household appliances, and finally this would lead to an increase in residential energy consumption [13]. Families with different incomes have different energy consumption situations. Feng et al. and Niu et al. [4, 8]studied the influencing factors of energy consumption of urban and rural residents in China. Their findings showed that household energy consumption of high-income families was more than that of low-income families and the direct energy consumption of urban residents was more than that of rural residents. Cayla et al. [3] analyzed the energy consumption situation of families with different incomes and concluded that even high-income families would suffer from great pressure when the proportion of household energy consumption was rather high. However, Sanquist et al. [14] proved that there was not a direct link between electricity use and rural income generation in the short term in United States. In addition, many studies investigated the influence of other factors' except income. Lucas et al. [15] found that the family size, age and household time had impact on residential energy consumption. Druckman and Jackson, Kaza, Miah et al., and Wiesmann et al. [1, 5, 16-17]suggested that house type, location and other factors would inflence residential energy consumption. Ekholm et al. [2] found that personal preference was one of the major factors that influence household energy consumption in India. Liu [18] confirmed policy and social norms, and past experience may have a positive correlation with household electricity-saving behavior.

Few scholars have studied urbanization's influence on energy and electricity consumption. Hiemstra-van der Horst and Hovorka [19] studied urbanization's influence on energy consumption in Sub-Saharan Africa and the results indicated that there was no obvious "energy transition" phenomenon, and they thought it has little to do with the change in household energy conversion mode. Liu [20] examined the relationship between urbanization and energy consumption. He found that urbanization's leading role in energy consumption became continuously less significant and the contradiction between urbanization and energy consumption could be eased only in the case of the combined increase in both energy efficiency and urbanization. Bartusch et al. [21] thought that variance in residential electricity consumption cannot be fully explained by independent variables related to household and building characteristics alone.

The above literature have shown that factors such as family income, housing type, location, personal preferences, family size, age and household time have impact on residential energy and electricity consumption. They only studied on the factors' impact on total household energy and 
electricity consumption but did not analyze per capital residential electric consumption and urbanization's impact on per capita residential electricity consumption. Therefore, this paper differs from the previous studies [19-20] with a focus on the analysis of impacts on electricity consumption caused by the changes in population structure, income and electricity consumption tendency in the process of urbanization in China.

\section{Methodology and Data}

\section{Methodology}

In order to measure urbanization's influence on residential electricity consumption, firstly the equation of urbanization rate and per capita residential electricity consumption was established. The amount of per capita residential electricity consumption $(P E$ )equals to the sum of the products of the amount of per capita electricity consumption of urban residents( $\left.P E_{1}\right)$ and urbanization population rate $\left(R_{1}\right)$ and the products of the amount of per capita electricity consumption of rural residents $\left(P E_{2}\right)$ and the proportion of rural population $\left(R_{2}\right)$,therefore the equation can be formulated as follows.

$$
P E=\sum_{i} P E_{i} \times R_{i}=\sum_{i} \frac{E_{i}}{Y_{i}} \times \frac{Y_{i}}{P_{i}} \times R_{i}=\sum_{i} E T_{i} \times D I_{i} \times P R_{i}
$$

Where, $Y$ represents residents' disposable income, $E$ represents residential electricity consumption, $P$ represents population, $i=1$ represents urban areas, $i=2$ represents rural areas, $E T_{i}=\frac{E_{i}}{Y_{i}}$ represents the electricity consumption tendency of residents and $D I_{i}=\frac{Y_{i}}{P_{i}}$ represents per capita disposable income of residents.

Change in per capital residential electricity consumption( $\triangle P E_{\text {tot }}$ ) can be decomposed into electricity consumption tendency effect $\left(\Delta P E_{e t}\right)$, per capita income effect $\left(\triangle P E_{D I}\right)$ and population structure effect $\left(\triangle P E_{R P}\right)$. Electricity consumption tendency effect reflects the impact on the change in the amount of per capita disposable income of residents caused by the change in the ratio of residential electricity consumption to disposable income. Income effect represents the impact on the change in the amount of per capita disposable income of residents caused by the change in disposable income. Population structure effect reflects the effect of per capital residential electricity consumption caused by the change in the population of urban and rural residents during the process of urbanization.

$$
\Delta P E_{\text {tot }}=\Delta P E_{e t}+\Delta P E_{D I}+\Delta P E_{R P}
$$

According LMDI method [22], the changes in each effect of the reporting period (t) compared with those of the base period (0) can be decomposed as follows:

$$
\begin{aligned}
& \triangle P E_{E T}^{t}=\sum_{i} L\left(P E_{i}^{t}, P E_{i}^{0}\right) \ln \left(\frac{E T^{t}}{E T^{0}}\right) \\
& \triangle P E_{D I}^{t}=\sum_{i} L\left(P E_{i}^{t}, P E_{i}^{0}\right) \ln \left(\frac{D I^{t}}{D I^{0}}\right) \\
& \triangle P E_{R P}^{t}=\sum_{i} L\left(P E_{i}^{t}, P E_{i}^{0}\right) \ln \left(\frac{R P^{t}}{R P^{0}}\right)
\end{aligned}
$$




$$
\text { Among them, } L\left(P E_{i}^{t}, P E_{i}^{0}\right)=\frac{P E_{i}-P E_{0}}{\ln P E_{i}-\ln P E_{0}}
$$

\section{Data}

The original data come from "China Statistical Yearbook (1997-2012)" and "China Energy Statistical Yearbook (2009-2012)". This research focuses mainly on residential electricity consumption. Per capital residential electricity consumption in rural areas is referring to the ration of the total residential electricity consumption in rural areas to the population of rural areas. Per capital residential electricity consumption in urban areas is referring to the ration of the total residential electricity consumption in urban areas to the population of urban areas.

\section{Result and Discussion}

\section{Analysis on the Influence of Each Factor in 1997-2011}

As shown in Table 1, among the influencing factors of per capita residential electricity consumption, income effect is the main reason for the increase in per capital residential electricity consumption, followed by population structure effect and electricity consumption tendency effect. Among them, the value of income effect is positive, i.e. the increase in income will promote the increase of per capita electricity consumption. The value of population structure effect is positive as well, and the higher the proportion of urban residents is, the more per capital residential electricity is consumed. However, the value of electricity consumption tendency effect changes irregularly. The value of electricity consumption tendency effect is negative from 1998 to 2002, in 2008, 2010 and 2011. In these periods, residents' consumption tendency is electricity-saving consumption which is helpful for controlling the increase in electricity consumption. The value of electricity consumption tendency effect is positive in 1997, 2001, from 2003 to 2007 and in 2009. In these periods, residents' consumption tendency is electricity-wasting consumption which will promote the increase in electricity consumption.

Table 1 Change of per capital residential electricity consumption decomposed, 1997-2011

\begin{tabular}{|c|c|c|c|c|}
\hline $\begin{array}{c}\text { Original } \\
\text { data }\end{array}$ & $\begin{array}{c}\text { Total variation } \\
\text { value }\end{array}$ & $\begin{array}{c}\text { Electricity } \\
\text { consumption } \\
\text { tendency effect }\end{array}$ & Income effect & $\begin{array}{c}\text { Population } \\
\text { structure effect }\end{array}$ \\
\hline 1997 & 0.00134 & 0.00026 & 0.00079 & 0.00029 \\
\hline 1998 & 0.00069 & -0.00014 & 0.00055 & 0.00028 \\
\hline 1999 & 0.00054 & -0.00047 & 0.00075 & 0.00026 \\
\hline 2000 & 0.00078 & -0.00018 & 0.00071 & 0.00025 \\
\hline 2001 & 0.00142 & 0.00009 & 0.00109 & 0.00024 \\
\hline 2002 & 0.00145 & -0.00022 & 0.00144 & 0.00023 \\
\hline 2003 & 0.00262 & 0.00091 & 0.00147 & 0.00024 \\
\hline 2004 & 0.00297 & 0.00046 & 0.00229 & 0.00022 \\
\hline 2005 & 0.00457 & 0.00171 & 0.00262 & 0.00024 \\
\hline 2006 & 0.00422 & 0.00080 & 0.00313 & 0.00028 \\
\hline 2007 & 0.00645 & 0.00088 & 0.00526 & 0.00031 \\
\hline 2008 & 0.00289 & -0.00269 & 0.00537 & 0.00021 \\
\hline 2009 & 0.00419 & 0.00042 & 0.00352 & 0.00024 \\
\hline 2010 & 0.00210 & -0.00368 & 0.00551 & 0.00027 \\
\hline 2011 & 0.00429 & -0.00305 & 0.00716 & 0.00018 \\
\hline
\end{tabular}




\section{Decomposition of Per Capital Residential Electricity Consumption in Urban and Rural Regions}

According to Equation (1), per capital residential electricity consumption in rural and urban regions equal to the products of electricity consumption tendency and their income. LMDI method is used to decompose them. As shown in Figure 2, urban residents' income effect is greater than their electricity consumption tendency effect and it is the main reason for the increase in per capita electricity consumption. During the majority period, electricity consumption tendency effect in urban regions controls the growth of per capita electricity consumption. However, in 2003 and 2005, electricity consumption tendency effect in urban regions is positive which means that in these two years it promotes the increase in per capita residential electric consumption in urban regions. Seen from Figure 3, the result of the decomposition of per capital residential electricity consumption in rural regions is different from the result in urban regions. The electricity consumption tendency is positive in most time and it promotes the growth of per capital residential electric consumption in rural regions. Rural residents' income effect is less than the electricity consumption effect from 1997 to 2003 and in 2006. In these periods, the electricity consumption is the main reason for the growth of per capital electric consumption in rural regions. The income effect is the main reason in 2004, 2005 and from 2007 to 2011.
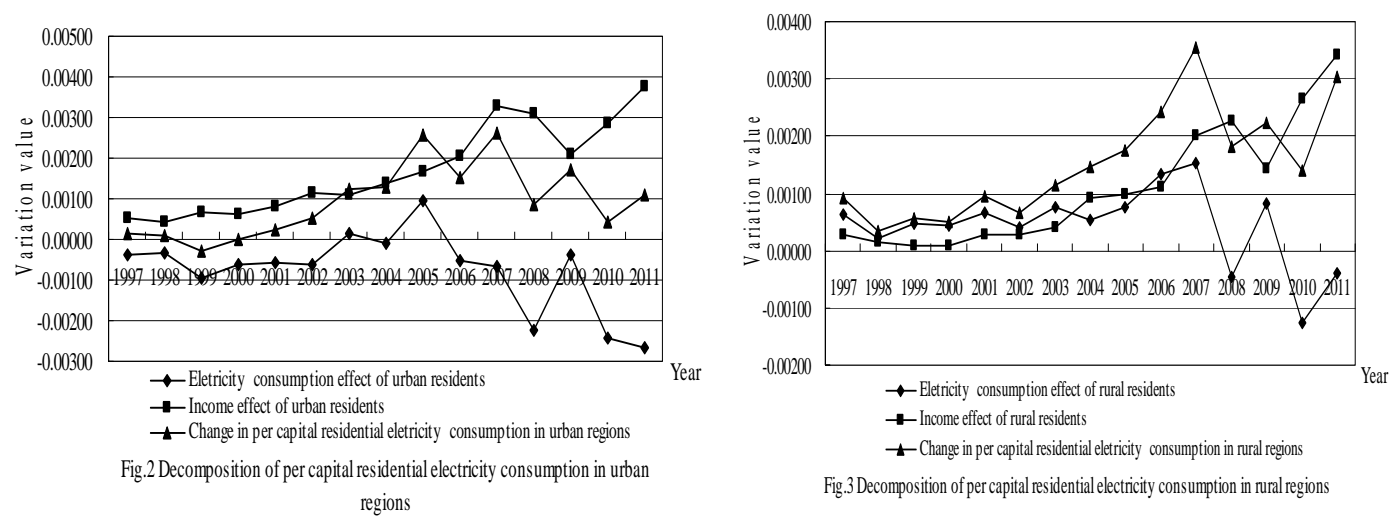

\section{Decomposition of Electricity Consumption Tendency Effect}

Electricity consumption tendency effect is mainly reflected by the relative growth of electricity consumption. As can be seen from Figure 4, electricity consumption tendency effect of rural residents is far higher than that of urban residents. This is because the wealthy rural residents began to consume more household electrical appliances. Washing machines, refrigerators, air conditioning and television have increased by 30.801\%、74.763\%、191.991\% and 36.249\% ${ }^{2}$ from 2001 to 2011 in rural regions. While, urban residents have owned enough household electrical appliances that their demand decreased. Washing machines, refrigerators, air conditioning and television have increased by $2.382 \% 、 6.798 \% 、 69.9 \%$ and $5.3 \%^{3}$ in urban regions. Besides, the rapid increase in consumption on household appliances in rural regions is also due to the relative policy implemented by Chinese government. In December 2008, Chinese government implemented the activity of "Household electrical appliances go to the countryside" that Chinese non-urban residents who purchased television, refrigerator, washing machine and other products would be offered subsidies that worth $13 \%$ of the products' price with the maximum subsidy of 2,000 yuan for television, 2500 yuan for refrigerator and 1000 yuan for washing machine. The above factors lead to the increase in the amount of household electrical appliances owned by rural residents and the increase in rural residents' electricity consumption. The proportion of electricity consumption in rural residents' total living expenses has gradually increased so that rural residents' electricity consumption tendency

\footnotetext{
$2{ }^{3}$ Calculated with the data originated from "China Statistical Yearbook"
} 
increased correspondingly.

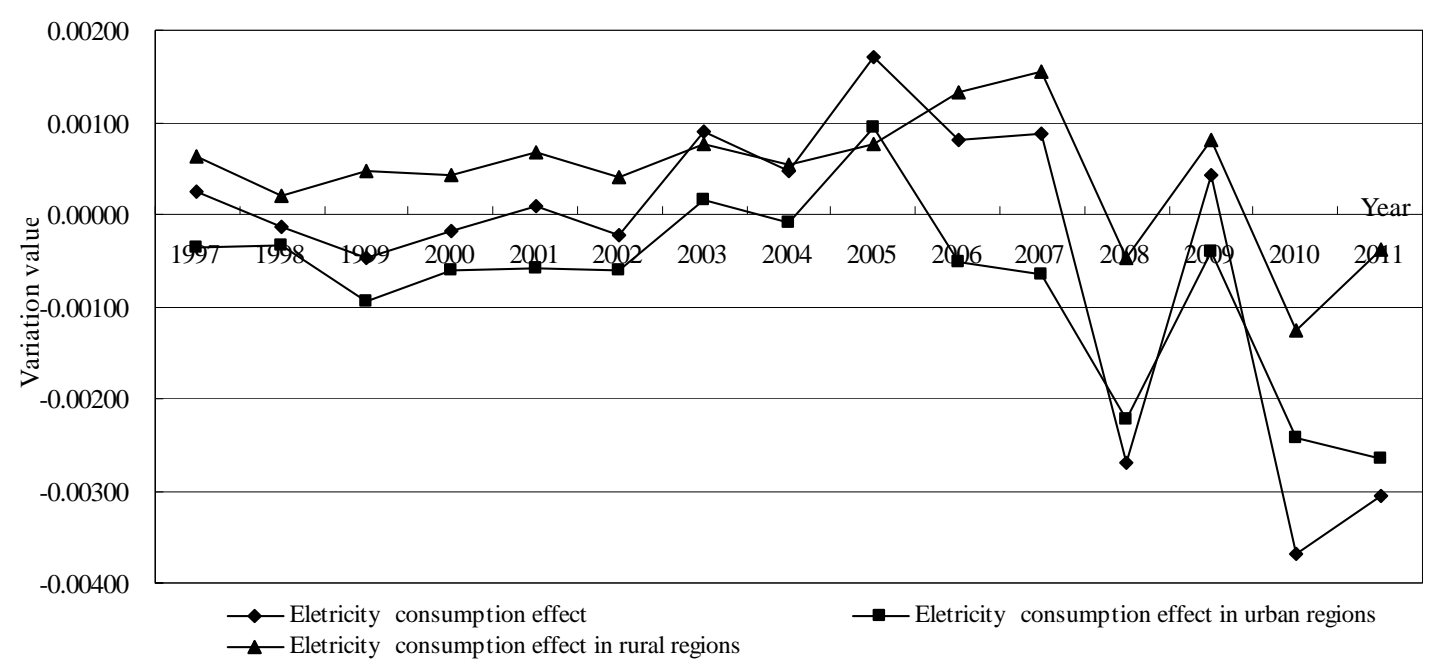

Fig.4 Decomposition of residents' electricity power consumption tendency

\section{Decomposition of Income Effect and Population Structure Effect}

Different from electricity consumption effect's appearance, income effect and population structure effect are reflected by the absolute amount of energy consumption, say the total annual per capital residential electricity consumption. As shown in Figure 5, income effect of both urban and rural residents increases, income effect is the mainly driving force of the total income effect and this effect is higher in urban regions than in rural regions. The value of the decreasing effect of the population proportion of rural residents is negative means that it hinders per capita residential electricity consumption's increasing trend, while the increasing effect of the population proportion of urban residents is positive means that it promotes the increase in per capita residential electricity consumption. Urban residents have higher-level income and greater purchasing power. Therefore, the number of household appliances owned by urban residents is much higher than that owned by rural residents. At the end of 2011, every 100 urban families own 1.551 times washing machines of rural families, 1.58 times refrigerators, 5.403 times air-conditioning and $1.171^{4}$ times television.
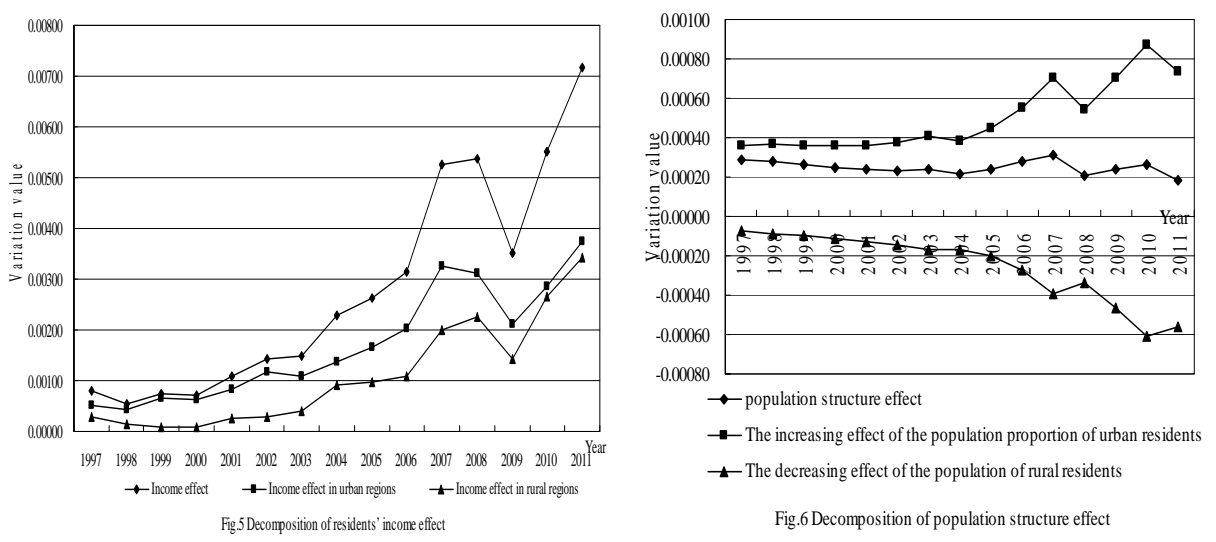

In order to control the increasing trend of per capita electricity consumption, it is necessary to control electricity consumption tendency effect and income effect. The "Tiered electricity pricing" for Chinese residential users has been implemented in July 1st, 2012 at national level. 29 provinces in China have announced their implementation plan by August 7th, 2012. 90\% of them raised the first ladder standard. However, the first ladder standard is unreasonable and requires adjustment for

${ }^{4}$ Calculated with the data originated from "China Statistical Yearbook" 
the actual situation of different regions. Besides, the government should guide residents' electricity consumption behaviors through rewards for saving electricity, regulations and policies. We should guide residents to form the green consumption habits and investments. The government should offer subsidies for residents investing in green industry, improving their return and rewarding families that save energy as well.

\section{Conclusion}

Over the last decade, the acceleration of Chinese urbanization has not only promoted the economic development in China, but also greatly increased Chinese electricity consumption. The increasing trend of per capital residential electricity consumption was evident. This study investigated the change of every factors in the process of urbanization in China and their impact on the change of per capital residential electricity consumption from 1997 to 2011, the main conclusions are as follows:

[1] During the majority of the period 1997-2011, income effect is the decisive influencing factor for per capital residential electricity consumption. Population structure effect is less decisive and electricity consumption tendency effect is the least decisive.

[2] Electricity consumption tendency effect in rural regions is much higher than that in urban regions and it is the main driving factor of change in energy consumption. The change of electricity consumption tendency is due to the increase in the residential income and national policy support.

[3] The income effect of urban and rural residents shows an increasing trend. The Income effect of urban residents is the main driving force of the total income effect.

\section{References}

[1] Druckman A, Jackson T. Household energy consumption in the UK: A highly geographically and socio-economically disaggregated model. Energy Policy. 2008;36:3177-92.

[2] Ekholm T, Krey V, Pachauri S, Riahi K. Determinants of household energy consumption in India. Energy Policy. 2010;38:5696-707.

[3] Cayla JM, Maizi N, Marchand C. The role of income in energy consumption behaviour: Evidence from French households data. Energy Policy. 2011;39:7874-83.

[4] Feng ZH, Zou LL, Wei YM. The impact of household consumption on energy use and CO2 emissions in China. Energy. 2011;36:656-70.

[5] Miah MD, Foysal MA, Koike M, Kobayashi H. Domestic energy-use pattern by the households: A comparison between rural and semi-urban areas of Noakhali in Bangladesh. Energy Policy. 2011;39:3757-65.

[6] Yu BY, Zhang JY, Fujiwara A. Representing in-home and out-of-home energy consumption behavior in Beijing. Energy Policy. 2011;39:4168-77.

[7] Dai HC, Masui T, Matsuoka Y, Fujimori S. The impacts of China's household consumption expenditure patterns on energy demand and carbon emissions towards 2050. Energy Policy. 2012;50:736-50.

[8] Niu SW, Zhang X, Zhao CS, Niu YZ. Variations in energy consumption and survival status between rural and urban households: A case study of the Western Loess Plateau, China. Energy Policy. 2012;49:515-27.

[9] Zhao XL, Li N, Ma CB. Residential energy consumption in urban China: A decomposition analysis. Energy Policy. 2012;41:644-53.

[10] Liu WL, Spaargaren G, Heerink N, Mol APJ, Wang C. Energy consumption practices of rural households in north China: Basic characteristics and potential for low carbon development. Energy 
Policy. 2013;55:128-38.

[11] Thomas BA, Azevedo IL. Estimating direct and indirect rebound effects for US households with input-output analysis. Part 2: Simulation. Ecol Econ. 2013;86:188-98.

[12] Zhang M, Guo FY. Analysis of rural residential commercial energy consumption in China. Energy. 2013;52:222-9.

[13] Crosbie T. Household energy consumption and consumer electronics: The case of television. Energy Policy. 2008;36:2191-9.

[14] Sanquist TF, Orr H, Shui B, Bittner AC. Lifestyle factors in U.S. residential electricity consumption. Energy Policy. 2012;42:354-64.

[15] Lucas IB, Hidalgo E, Gomez W, Roses R. Behavioral factors study of residential users which influence the energy consumption. Renew Energy. 2001;24:521-7.

[16] Kaza N. Understanding the spectrum of residential energy consumption: A quantile regression approach. Energy Policy. 2010;38:6574-85.

[17] Wiesmann D, Azevedo IL, Ferrao P, Fernandez JE. Residential electricity consumption in Portugal: Findings from top-down and bottom-up models. Energy Policy. 2011;39:2772-9.

[18] Liu HT, Guo JE, Qian D, Xi YM. Comprehensive evaluation of household indirect energy consumption and impacts of alternative energy policies in China by input-output analysis. Energy Policy. 2009;37:3194-204.

[19] Hiemstra-van der Horst G, Hovorka AJ. Reassessing the "energy ladder": Household energy use in Maun, Botswana. Energy Policy. 2008;36:3333-44.

[20] Liu YB. Exploring the relationship between urbanization and energy consumption in China using ARDL (autoregressive distributed lag) and FDM (factor decomposition model). Energy. 2009;34:1846-54.

[21] Bartusch C, Odlare M, Wallin F, Wester L. Exploring variance in residential electricity consumption: Household features and building properties. Appl Energy. 2012;92:637-43.

[22] Ang BW, Liu N. Handling zero values in the logarithmic mean Divisia index decomposition approach. Energy Policy. 2007;35:238-46. 